\title{
IDŐJÁRÁS
}

Quarterly Journal of the Hungarian Meteorological Service

Vol. 123, No. 3, July-September, 2019, pp. 295-312

\section{Towards an intelligent traffic control system using crowdsourcing, based on combined evaluation of weather information and accident statistics}

\author{
Mátyás Szántó* and László Vajta \\ Department of Control Engineering and Information Technology, \\ Faculty of Electrical Engineering and Informatics \\ Budapest University of Technology and Economics \\ Müegyetem rkp. 3, H-1111, Budapest, Hungary \\ *Corresponding authorE-mail:mszanto@iit.bme.hu
}

(Manuscript received in final form May 13, 2019)

\begin{abstract}
Weather conditions have both direct and indirect effects on road traffic. On the one hand, precipitation heavily influences road traction as well as vehicle visibility, and on the other hand, medical meteorology phenomena - for example weather fronts - have a great effect on the driving ability and accuracy of drivers. Weather fronts - through their physiological effects - may cause the deterioration of human reaction times, and therefore increase the risk of accidents' occurrence in unexpected and hazardous traffic situations that would require quick intervention of drivers. In this article, our research regarding the relation between weather fronts and traffic accidents as well as between local meteorological parameters and weather fronts is presented.

In this article, a crowdsourcing-based methodology is presented, that is supported by a database, which is assembled using data that is far more heterogeneous with regard to acquisition frequency and quality, than those available previously. Using such a database, a driver aiding system can be created for use in cars currently supporting lower levels of autonomy. Such driver assistance systems would be capable of informing or, in a given situation, indirectly decrease the likelihood of the development of an emergency by warning the driver.
\end{abstract}

Key-words: weather fronts, traffic accidents, accident statistics, local weather and weather fronts, crowdsourcing, road safety, Hungary 


\section{Introduction}

Weather conditions and their effects on humans have been studied thoroughly in the past century by biometeorologists and medical meteorologists (Everett, 1879; Örményi, 1975). According to the research of Örményi, the most significant atmospheric change, which has the most considerable effect on the human body, is the transition of weather fronts. Numerous researchers have conducted investigations ever since in order to understand the physiological consequences that these phenomena might have on the population and especially on individuals with certain conditions - e.g. rheumatic diseases -, that make them more weather sensitive than others (Dúll, 2014). In a study, conducted using data collected from individuals across two countries, Germany and Canada (von Mackensen et al., 2005 ) concluded that more than half of the population of these countries consider themselves weather sensitive $-54.5 \%$ in Germany and $61 \%$ in Canada.

Most of the studies in the field of medical meteorology are considered longitudinal studies, since their main aim is to identify the statistical correlations between time series of meteorological and medical records (Bucher and Haase; 1993). Consequently, these studies focus on the direct medical effect of weather conditions on humans. Von Mackensen et al. (2005) listed symptoms, such as headache/migrane, lethargy, fatigue, and irritation in their survey: their results show that many individuals are affected by these conditions as a result of their weather-sensitiveness.

Such symptoms and health conditions may have considerable indirect impact on road safety as well. Brown (1994) suggests that as much as $25 \%$ of singlevehicle road accidents may be traced back to issues regarding driver fatigue: weariness could deteriorate individual's performance in tasks that require sustained vigilance, selective attention, and complex decision-making.

The influence of local weather conditions, e.g., temperature, precipitation, wind, on traffic accidents has been studied broadly in the past decade for Hungary (Vécsei and Kovács, 2014) and for other countries (Jaroszweski and McNamara, 2014; Shahid and Minhans, 2016; Darzi et al., 2018) as well. Darzi et al. (2018) studied the effect of local meteorological phenomena as well as fatigue, achieved through sleep deprivation, on the driver vigilance using a purpose-built driving simulation.

This article, however, presents a different approach: in Section 2, using data available over a time span of 10 years (within 2001 and 2010), road accident statistics are assessed in a longitudinal fashion, in order to identify some trends present between weather front transitions and variation in the distributions of number of traffic accidents. Secondly, another statistical study is presented whose aim is to identify trends in front type transitions by comparing and selecting locally obtainable weather data, e.g., local temperature values, with the use of a detailed database. Then, on the basis of the results of these two analyses, a crowdsourcing-based approach is presented for road database production that 
could be the foundation of a driver aiding system ultimately beneficial for increasing road safety.

\section{The effect of weather conditions on road safety}

\subsection{Original and modified databases}

For conducting the study presented in this article, the same database was used as in Vécsei and Kovács (2014). That is, the database consisted of hourly statistics of domestic - i.e., Hungarian - road traffic accidents (source: KSH data collection, data provider: police OSAP1009) and the extensive local weather data recorded at selected meteorological observatory sites (Budapest, Pécs, Szeged, Debrecen, Szombathely, Győr, Nagykanizsa, and Siófok) of the Hungarian Meteorological Service for the same time-period. The database was initially created by acquiring and assembling data collected on an hourly basis between January 1, 1990 and December 31, 2010. However, the data used in this article were summed or averaged over individual days - that is, summed in case of accident statistics and averaged for weather related data. The database was also cropped for the ten-year time-period of January 1, 2001 and December 31, 2010. The reason for this data reduction was the database containing the front types registered for Hungary.

Records of front types in this latter database has been made available for the purpose of this study on a daily basis between January 1, 2001 and December 31, 2010, courtesy of the Data Supply Department of the Hungarian Meteorological Service. The main front types can be found in Table 1.

Table 1. Front types and their codes in the used database

\begin{tabular}{lccccc}
\hline Front type & No front & $\begin{array}{c}\text { Stable } \\
\text { warm front }\end{array}$ & $\begin{array}{c}\text { Unstable } \\
\text { warm front }\end{array}$ & $\begin{array}{c}\text { Unstable } \\
\text { cold front }\end{array}$ & $\begin{array}{c}\text { Stable } \\
\text { cold front }\end{array}$ \\
Code in database & 1 & 2 & 3 & 4 & 5 \\
\hline
\end{tabular}

For days, when two different front types have been recorded in Hungary, two separate codes were given in the database - e.g., 3,4 or 1,5. However, in the study presented in this paper, only those front codes have been used which were unambiguous - i.e., only one type of weather front was indicated for a certain day for the whole country. This measure, while reducing the amount of data, enables a more precise statistical evaluation of the available records. 
The thus assembled and cropped database has been used for carrying out the study presented below. Every record contains hourly data over the above specified 10-year time-period for traffic accident, local and medical meteorology related data information, including ${ }^{1}$ :

- Front type for the given day;

- Front type for the previous day;

- Temperature and temperature difference (for the selected cities);

- Cumulative precipitation and cumulative precipitation difference;

- Wind and wind difference;

- Absolute number of traffic accidents within city limits;

- Absolute number of traffic accidents outside city limits;

- Timestamp.

The above database containing records regarding local weather and traffic accidents, which has been made available for the purpose of this study, is relatively outdated - i.e., some data have been collected almost twenty years prior to the preparation of this paper. Since the database has 3652 records over the assessed years, it is safe to say that it is representative of the chosen time-period.

However, one of the main purposes of this study was to identify possible connections between medical meteorological phenomena and accident statistics. The fact that several studies concerned with this effect written several decades apart (Everett, 1879; Örményi, 1975) concluded into similar results regarding the effect of meteorological weather data on human behavior suggests that the connection between the two aspects are not subject to change significantly over time. This also suggests that the conclusions of this paper are applicable for the traffic circumstances of present days.

The amount of traffic flow on the roads plays a major role in the number of accidents occurring. Fluctuation for vehicles on the road can be observed on different scales. The daily fluctuation of road usage of Hungarian roads in particular is shown in Kovács (2013). Karacusu et al. (2011) have studied this relationship in depth for Eskisehir, Turkey for daily, weekly, and seasonal vehicle number fluctuations and have concluded that more vehicles present on the roads means greater probability for accidents. Because of this fluctuation, a normalization step has been introduced for the number of accidents in the database. First, the number of accidents has been averaged between January 1, 2001 and December 31, 2010 for regular days - i.e., working Mondays to Fridays and ordinary weekend Saturdays and Sundays. The mean values for this period are shown in Table 2.

\footnotetext{
${ }^{1}$ Difference is always calculated between the current and the previous record
} 
Table 2. Mean number of accidents for different 'regular' days for the time-period between January 1, 2001 and December31, 2010

\begin{tabular}{lccccccc}
\hline \hline \multirow{2}{*}{$\begin{array}{c}\text { Mean number of } \\
\text { accidents }\end{array}$} & \multicolumn{7}{c}{ Days of the week } \\
\cline { 2 - 8 } & Monday & Tuesday & Wednesday & Thursday & Friday & Saturday & Sunday \\
\hline \hline Budapest & 11.74 & 11.53 & 11.53 & 11.73 & 12.67 & 9.21 & 7.40 \\
Szeged & 0.84 & 0.81 & 0.83 & 0.90 & 0.91 & 0.78 & 0.51 \\
Pécs & 0.85 & 0.86 & 0.83 & 0.88 & 1.00 & 0.70 & 0.61 \\
Szombathely & 0.51 & 0.48 & 0.48 & 0.49 & 0.61 & 0.43 & 0.31 \\
\hline $\begin{array}{l}\text { Total within city } \\
\text { limits }\end{array}$ & 37.32 & 36.17 & 37.09 & 37.95 & 43.50 & 36.27 & 27.37 \\
$\begin{array}{l}\text { Total outside city } \\
\text { limits }\end{array}$ & 14.83 & 14.29 & 14.31 & 15.02 & 18.53 & 20.30 & 16.56 \\
\hline
\end{tabular}

In the case of the database used for this study, the difference of the traffic is also rather significant. After identifying the days, that are possible outliers, meaning the mean accident values are higher and lower than the total mean, a similarity test has been carried out for the number of accidents that occurred within and outside city limits on the identified days (Fridays and Sundays). It was found, that the similarity test of the accident numbers on the given days resulted in significances of under 0.0005 (Fig. 1). This showed, that the normalization step was indeed necessary before the accident values were compared.

Hypothesis Test Summary

\begin{tabular}{|llll|}
\hline \multicolumn{1}{|c|}{ Null Hypothesis } & \multicolumn{1}{c|}{ Test } & Sig. & Decision \\
\hline & $\begin{array}{l}\text { The distribution of Number of } \\
\text { accidents within city limits is the } \\
\text { same across categories of } \\
\text { Grouping variable. }\end{array}$ & $\begin{array}{l}\text { Independent- } \\
\text { Samples } \\
\text { Mann- } \\
\text { Whitney U } \\
\text { Test }\end{array}$ & $.000 \begin{array}{l}\text { Reject the } \\
\text { null } \\
\text { hypothesis. }\end{array}$ \\
\hline $\begin{array}{l}\text { The distribution of Number of } \\
\text { accidents outside city limits is the } \\
\text { same across categories of } \\
\text { Grouping variable. }\end{array}$ & $\begin{array}{l}\text { Independent- } \\
\text { Samples } \\
\text { Mann- } \\
\text { Whitney U } \\
\text { Test }\end{array}$ & .000 & $\begin{array}{l}\text { Reject the } \\
\text { null } \\
\text { hypothesis. }\end{array}$ \\
\hline
\end{tabular}

Asymptotic significances are displayed. The significance level is .05 .

Fig. 1. Results of similarity tests of accident distributions within and outside city limits for the possible outlier days - rejecting the null hypothesis, i.e., the distributions are considered not similar. 
According to the database, there have only been 21 Fridays that were holidays in Hungary during this ten-year interval. However, this fact has a significant effect on the mean values of number of accidents occurring on these days: excluding holidays caused a daily increase from 42.87 to 43.50 .

In Table 2, a two orders of magnitude difference in daily mean accident occurrences can be observed between different cities. This difference can be traced back to the sheer number of cars owned in the two areas. According to data provided by the Hungarian Central Statistical Office (KSH, 2018, 2019), in 2002, 594246 cars were registered in Budapest, which is almost six times as much as the number of cars registered for the whole of Baranya county (100 611) - the capital of which is the city of Pécs. For perspective: the total population of Baranya county was 404 709, whereas the same figure for Budapest was 1719342 at the beginning of 2003.

Because of the big gap between different urban areas, only the total number of accidents outside and within city limits has been used in this study. Using the mean values in Table 2, total daily accident numbers have been normalized. The thus calculated variables have been introduced in the database:

- Normalized number of traffic accidents within city limits;

- Normalized number of traffic accidents outside city limits.

The weekly distributions of mean accident numbers are visualized in Figs. 2 and 3 for within and for outside city limits, respectively. Different trends can be identified for within-city and outside-city traffic flow in these figures.

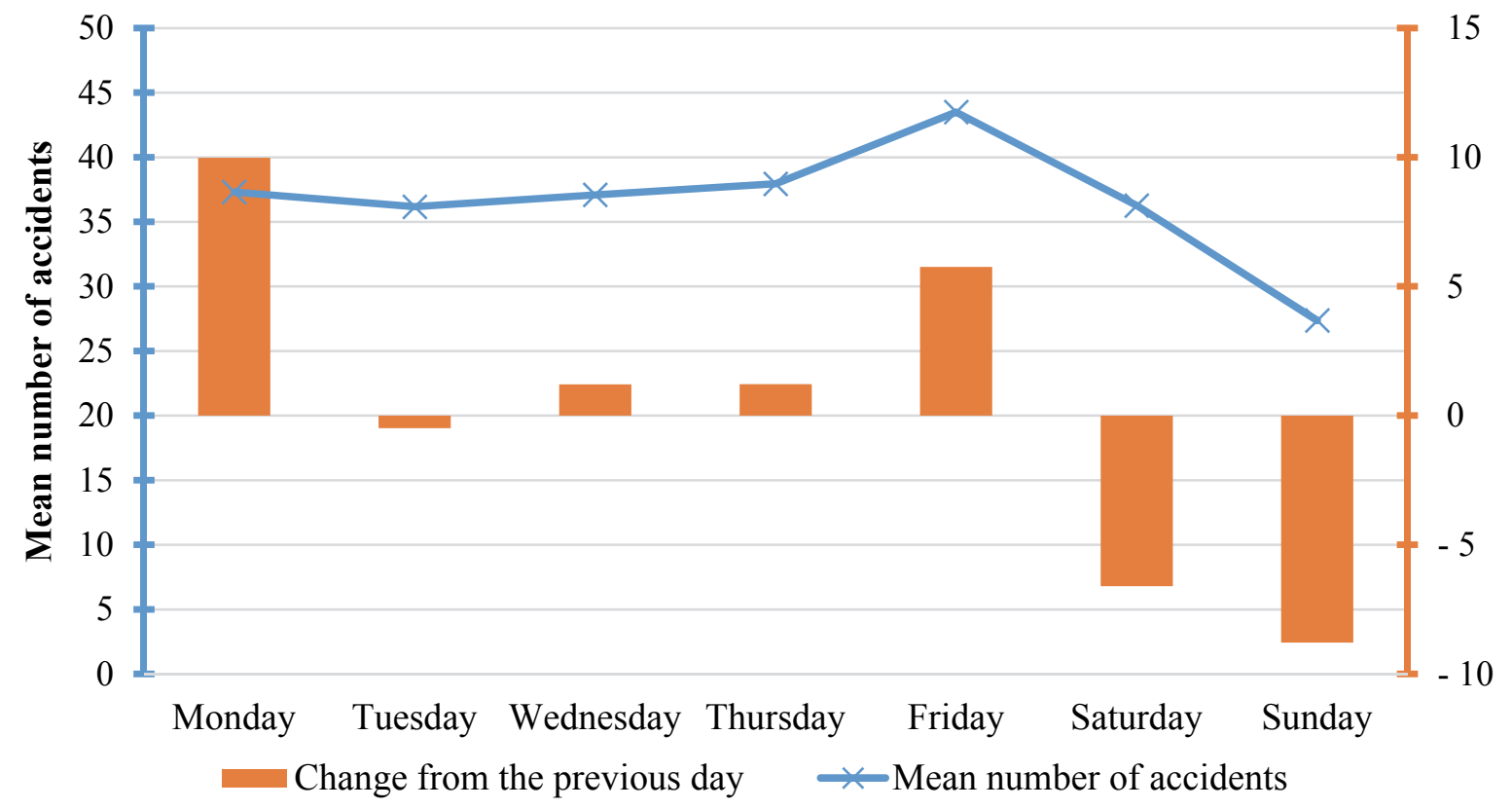

Fig. 2. Mean number of accidents within city limits for different regular days for the timeperiod between January 1, 2001 and December 31, 2010. 


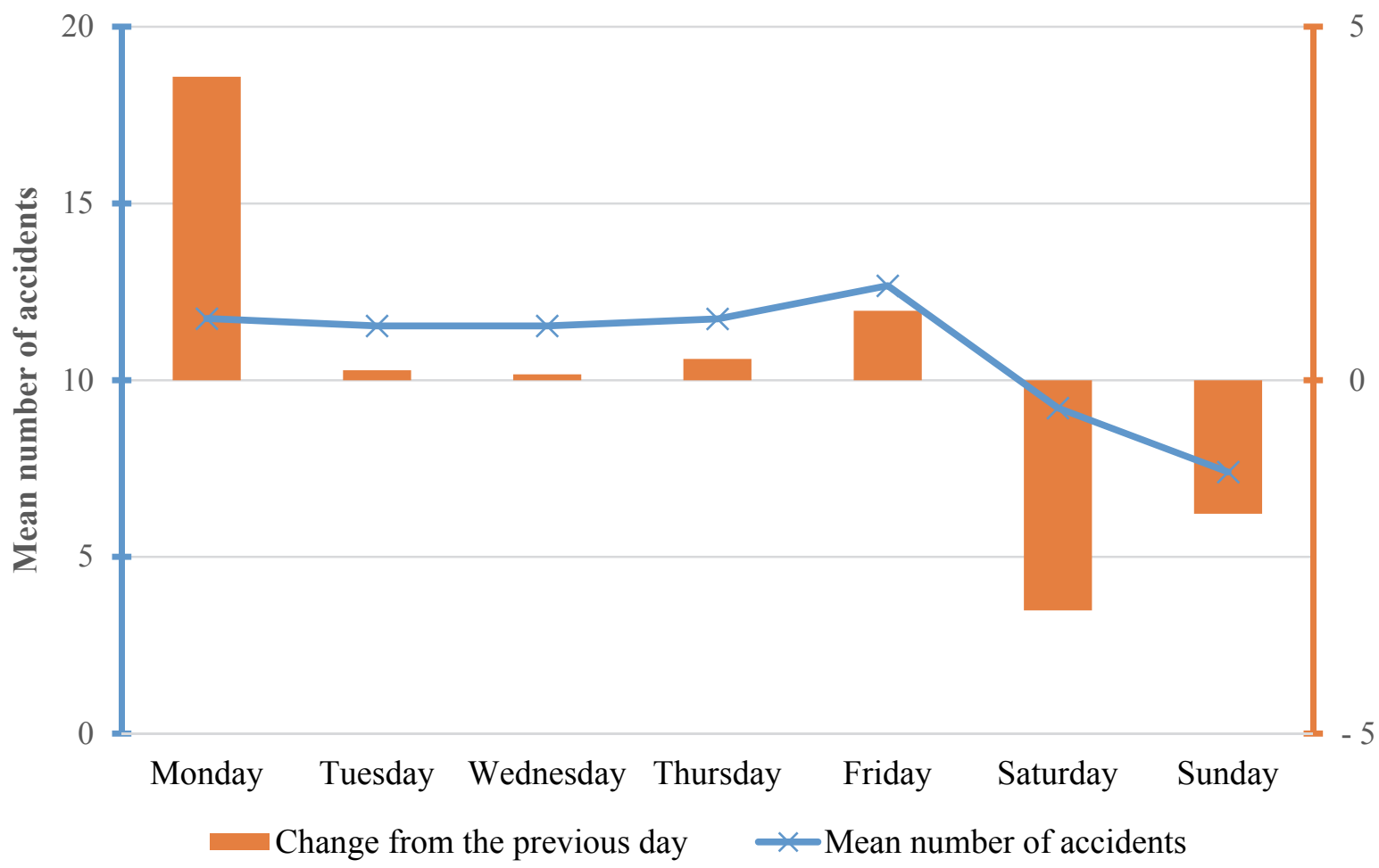

Fig. 3. Mean number of accidents outside city limits for different regular days for the timeperiod between January 1, 2001 and December 31, 2010.

\subsection{Statistical analysis of the relationship between weather fronts and traffic accidents}

The used environment for the statistical tests and visualization was IBM SPSS Statistics 23 version (Ketskeméty et al., 2011).

Using the above-introduced databases, a three-step statistical test-sequence has been developed in order to identify the possible relationships between weather phenomena and traffic safety. More specifically, an attempt has been made to find trends of weather front transition-related change in the number of accidents that occur on the roads. The test sequence consisted of the following steps:

1) Normality assessment: The variables of normalized accident occurrences have been tested using a parametric test. That is, each independent sample has been tested against the null hypothesis, that they were normally distributed around their mean value. For sample sizes smaller than 2000 elements, the Shapiro-Wilk test is used, otherwise, the normality may be tested using the Kolmogorov-Smirnov test. This test step, therefore, has been carried out using the Shapiro-Wilk test at a significance level of $0.05-$ or 
$5 \%$. As a part of the normality assessment, the distributions of the variables have been visualized using their histograms. The results of this step are shown in Fig. 4.

2) Mean value comparison: This step was introduced in order to manually assess the relation of the mean values of two variables, i.e., normalized accident numbers in case of no front transition versus the case of front transition. It involved the visualization of the two variables overlaid on each other by means of a stacked histogram. Using this step, the preliminary direction of change between the two variables, i.e., increase or decrease, could have been established. The results of this step can be observed in Fig. 5.

3) Similarity test of distributions: In this step, the hypothesis, that the independent variables were sampled from the same distribution has been tested. The significance level used for the test of this step was also 5\%. The results of this step are shown in Fig. 6.

For step 3) of the above described test sequence, an independent samples nonparametric test was used, since the normality of the samples' underlying distributions could not be granted in all cases. The selected variables, however, met the requirements for the Mann-Whitney U test in all cases, and considering the arguments made by Sawilowsky (2005), this test proved to be the most robust for the testing of the significant similarity of the samples.

The output of the test sequence of the comparison of distributions of normalized accident numbers outside city limits is shown in Figs. 4, 5, and 6 . Test case: no front transition from unstable cold front versus transition from no front to unstable cold front. 
1) Normality assessment and histogram of distribution of normalized number of accidents outside city limits

a) No front to unstable cold front transition

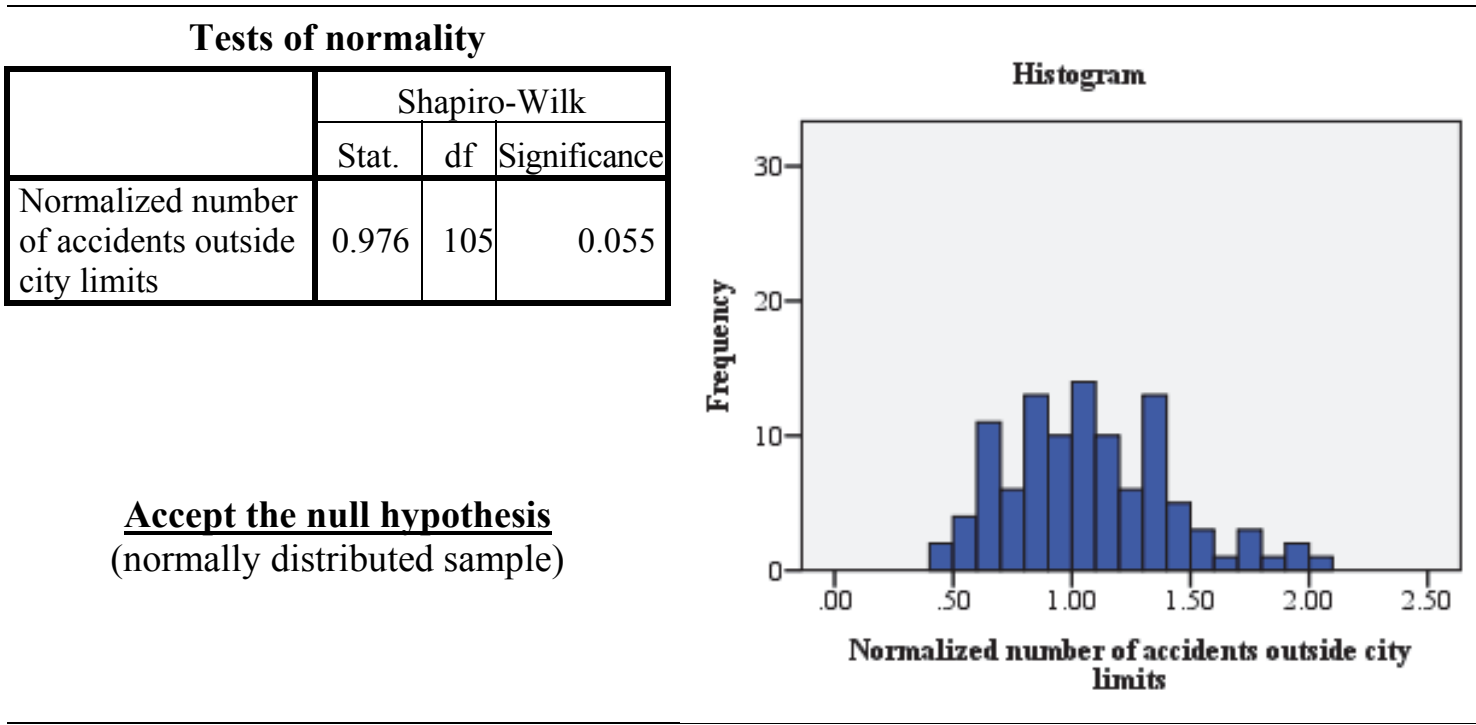

b) No transition from unstable cold front

\begin{tabular}{|l|r|r|r|}
\hline \multicolumn{1}{|c|}{ Tests of normality } \\
\cline { 2 - 4 } & \multicolumn{3}{|c|}{ Shapiro-Wilk } \\
\cline { 2 - 4 } & Stat. & df & Significance \\
\hline $\begin{array}{l}\text { Normalized number } \\
\text { of accidents outside } \\
\text { city limits }\end{array}$ & 0.972 & 190 & 0.001 \\
\hline
\end{tabular}

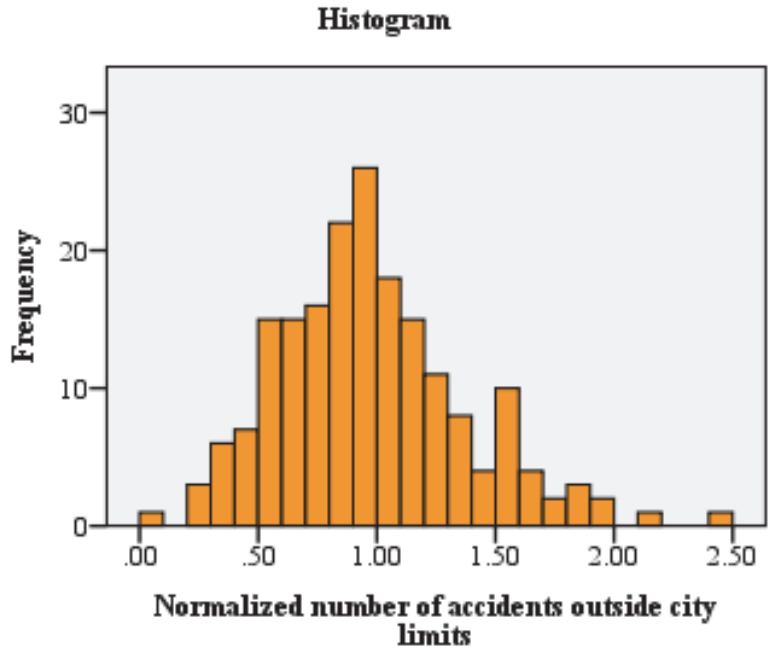

Fig. 4. Output of the normality assessment and histograms step. Test case: outside city limits; no front transition from unstable cold front versus transition from no front to unstable cold front. $d f$ is the degree of freedom of the sample, which is equal to $N-1$, where $N$ is the size of the sample. 


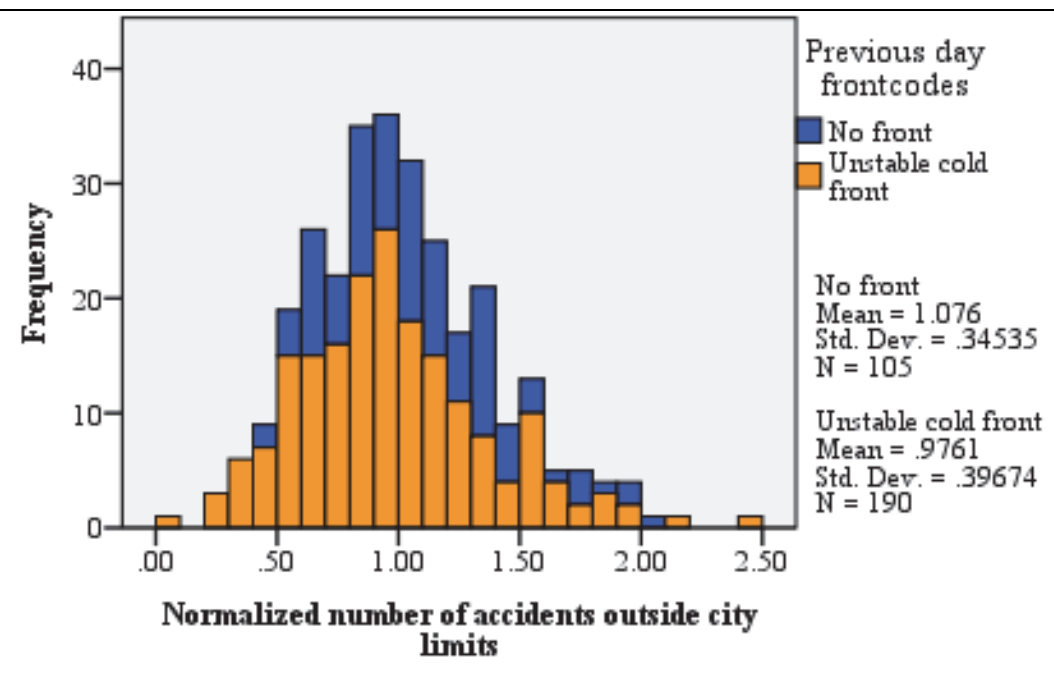

Higher mean value in case of no front to unstable cold front transition - increase

Fig. 5. Output of mean value comparison step. Test case: outside city limits; no front transition from unstable cold front versus transition from no front to unstable cold front.

\section{3) Similarity test of distributions}

\begin{tabular}{|l|lll|}
\hline \multicolumn{4}{|c|}{ Hypothesis Test Summary } \\
\hline \multicolumn{1}{|c|}{ Null Hypothesis } & \multicolumn{1}{c|}{ Test } & Sig. & Decision \\
\hline 1 & $\begin{array}{l}\text { The distribution of normalized } \\
\text { number of accidents outside city } \\
\text { limits is the same across } \\
\text { categories of grouping variable. }\end{array}$ & $\begin{array}{l}\text { Independent- } \\
\text { Mann- } \\
\text { Whitney U } \\
\text { Test }\end{array}$ & .013 \\
\hline
\end{tabular}

Asymptotic significances are displayed. The significance level is .05 .

Reject the null hypothesis - the difference of the distributions is significant

Fig. 6. Output of similarity test of distributions step. Test case: outside city limits; no front transition from unstable cold front versus transition from no front to unstable cold front.

The above introduced test sequence has been carried out on several test cases - i.e., no front transition versus front transition pairs. The results of these test sequences are summarized in Table 3. 
Table 3. Test sequence results for different test cases

\begin{tabular}{|c|c|c|c|c|}
\hline \multicolumn{2}{|c|}{ Test cases } & \multicolumn{3}{|c|}{$\begin{array}{c}\text { Difference in normalized number of accidents in case of front } \\
\text { transitions }\end{array}$} \\
\hline $\begin{array}{c}\text { Front } \\
\text { transition } \\
\text { types } \\
\end{array}$ & $\begin{array}{l}\text { No transition } \\
\text { front type }\end{array}$ & $\begin{array}{l}\text { Outside city limits } \\
\text { (significance) }\end{array}$ & $\begin{array}{l}\text { Within city limits } \\
\text { (significance) }\end{array}$ & $\begin{array}{l}\text { Number of } \\
\text { cases }\end{array}$ \\
\hline $\mathrm{NF}$ to UC & $\mathrm{UC}$ & Increase $(0.013)$ & Increase $(0.001)$ & 295 \\
\hline $\mathrm{NF}$ to $\mathrm{SC}$ & $\mathrm{SC}$ & Increase $(0.075)$ & Increase $(0.041)$ & 74 \\
\hline NF to SW & SW & Decrease $(0.167)$ & Decrease $(0.854)$ & 234 \\
\hline NF to UW & UW & Increase $(0.529)$ & Increase $(0.457)$ & 174 \\
\hline $\mathrm{UC}$ to $\mathrm{NF}$ & $\mathrm{NF}$ & Increase $(0.008)$ & Decrease $(0.180)$ & 878 \\
\hline $\mathrm{SW}$ to $\mathrm{UC}$ & $\mathrm{UC}$ & Increase $(0.804)$ & Increase $(0.049)$ & 260 \\
\hline $\mathrm{UW}$ to $\mathrm{UC}$ & $\mathrm{UC}$ & Increase $(0.002)$ & Increase $(0.518)$ & 290 \\
\hline $\mathrm{SC}$ to $\mathrm{UC}$ & UC & Increase $(0.191)$ & Increase (0.698) & 214 \\
\hline
\end{tabular}

\begin{tabular}{|l|l|}
\hline \multicolumn{2}{|c|}{ Legend } \\
\hline NF & No front \\
\hline SW & Stable warm front \\
\hline UW & Unstable warm front \\
\hline UC & Unstable cold front \\
\hline SC & Stable cold front \\
\hline Increase is significant & \\
\hline $\begin{array}{l}\text { Increase is not } \\
\text { significant }\end{array}$ & \\
\hline Decrease is significant & \\
\hline $\begin{array}{l}\text { Decrease is not } \\
\text { significant }\end{array}$ & \\
\hline Significance level & 0.05 or 5\% \\
\hline
\end{tabular}

As a result of the null hypothesis of the independent samples Mann-Whitney U test, the lower the test result's significance value - shown in brackets in Table 3 - the smaller the resemblance between the underlying distributions that the two variables are sampled from. With this information in mind, we can observe that the only front transition that is followed by a significant increase in accident numbers both within and outside city limits is the 'no front to unstable cold front' transition. The significance levels in the case of this transition are among the lowest figures yielded by the test sequences. 
From the test sequence results listed in Table 3, it can be identified that, based on the test data, the strongest relationship between the increasing number of traffic accidents and the transition of weather fronts can be shown in the case of the ' $n o$ front to unstable cold front' transition. These results endorse the cliché, that under the influence of some weather fronts, drivers in general become more precarious and upset.

\subsection{Suggesting front types based on local meteorological data}

Because the results of the previous section showed that the unstable cold front type might be linked to the most significant increase of traffic accidents, in the following sections of this paper, an effort is made to distinguish this front type number 4 in Table 1 - from the others.

The foundation beneath the weather front type-suggestions presented in this section was that based on the comparison and variation of the local meteorological parameters for different parts of the country - or different cities in this case - the current weather front might be presumed. For the case of this study, the temperature measured at 5 Hungarian cities (Szombathely, Pécs, Budapest, Debrecen, and Szeged) was used. In order to monitor the daily mean temperature difference between the 'neighboring' cities amongst these, 7 additional variables have been calculated in the database. The city-pairs, for which the temperature differences have been calculated for, are as follows:

- Budapest - Debrecen

- Budapest - Pécs

- Budapest - Szeged

- Budapest - Szombathely

- Pécs - Szombathely

- Pécs - Szeged

- Szeged - Debrecen

The direction of the subtractions have been decided by the geographical position of the cities. The meteorological processes, especially weather fronts, tend to approach Hungary from the northwest and move along towards the southeast, therefore the sequence of the cities in the subtractions have been selected accordingly. This caused the calculations to yield a negative difference if cold weather was approaching from the northwestern-western part of the country.

Another variable - a flag - has also been introduced for this analysis. If the largest absolute value among the temperature differences was the absolute value of an originally negative temperature difference, then the temperature decrease designator flag was set to true (or equal to 1) for the given day. Besides this, another yearly value had to be calculated in order for the front type suggestions 
to be effective, was the top percentile of the maximums of absolute values of temperature differences between cities in that year. Several values were considered during the research, but finally the 80th percentile proved to be the most effective. The percentile value has been calculated for the whole year. The 80th percentile values can be seen in Table 4 for each year of the research.

Table 4. 80th percentile values of the maximums of absolute values of temperature differences yearly

\begin{tabular}{ll}
\hline \hline Year & 80th percentile \\
\hline \hline 2001 & 3.3258 \\
\hline & \\
2002 & 3.1604 \\
2003 & 3.3850 \\
2004 & 3.2433 \\
2005 & 3.1242 \\
2006 & 3.2575 \\
2007 & 3.2658 \\
2008 & 2.8896 \\
2009 & 3.2208 \\
2010 & 3.1158 \\
\hline
\end{tabular}

Since in general, each year the two most common front types were no front and unstable cold front - latter is the front type of the greatest interest of this research -, the parameters most useful for filtering were identified as follows:

1) The mean temperature is lower in Szombathely than in Budapest.

2) The temperature decrease designator flag is true.

3) The maximums of absolute values of temperature differences between cities was in the 80th percentile.

Upon filtering the database with the above three parameters, a relatively effective unstable cold front suggestion could be reached. The use of the filtering algorithm on the front types are shown in Fig. 7, using the histograms of the yearly front type statistics. The two displayed histograms are displaying the unfiltered and the filtered frequencies of the front types for the year 2009. 

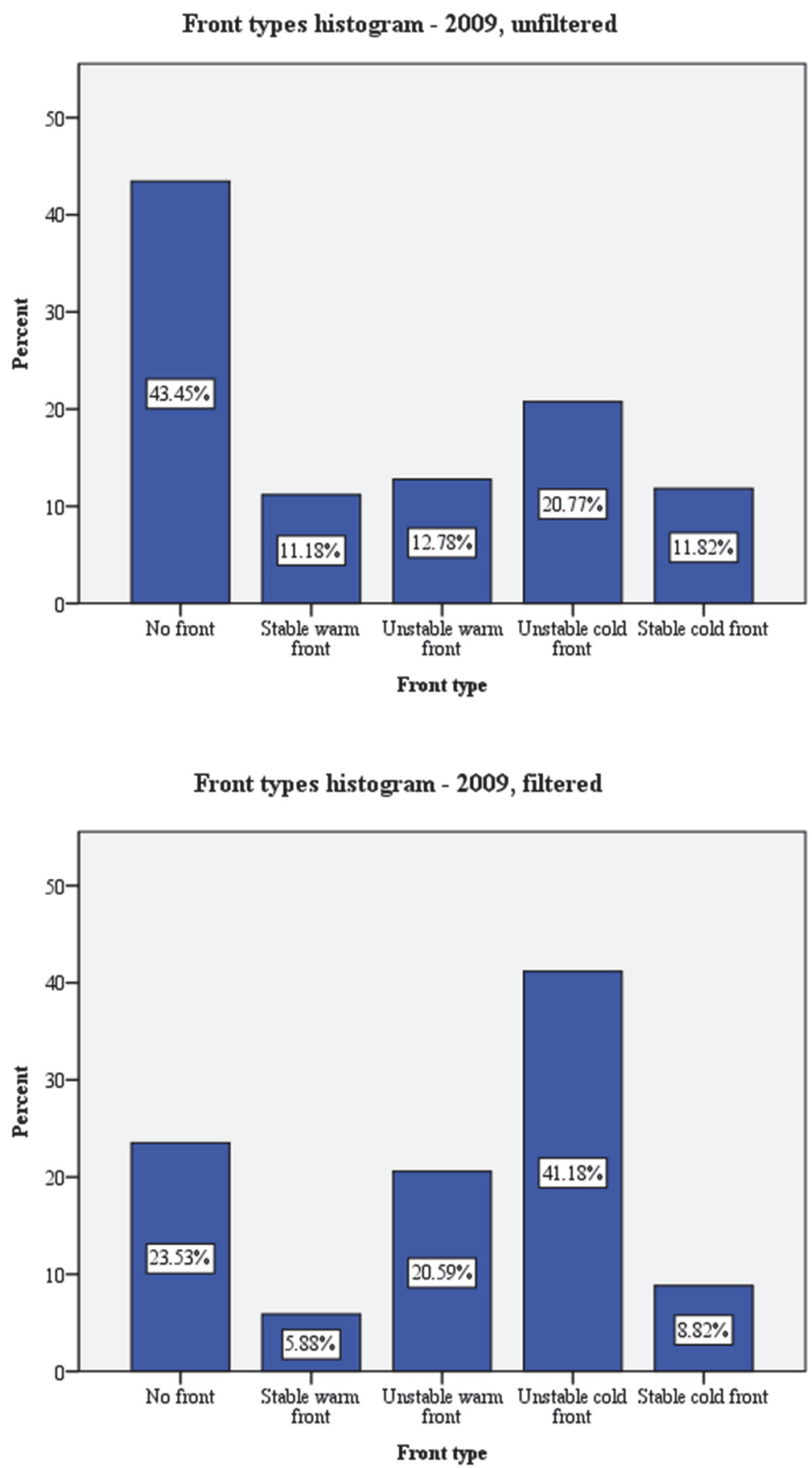

Fig. 7. Percentage histograms of front types in 2009 - unfiltered (above) and filtered (bottom) cases.

The above figure shows that the filtering criteria is fairly efficient for suggesting the front type 'unstable cold front'. The same filtering algorithm has been yearly for the time-period between 2000 and 2010, the results of which are shown in Table 5. 
Table 5. Yearly results of the front type filtering algorithm

\begin{tabular}{|c|c|c|c|c|c|c|c|}
\hline \multirow{2}{*}{ Year } & \multicolumn{3}{|c|}{$\begin{array}{l}\text { Unfiltered case } \\
\text { (percentages) }\end{array}$} & \multicolumn{3}{|c|}{$\begin{array}{l}\text { Filtered case } \\
\text { (percentages) }\end{array}$} & \multirow{2}{*}{$\begin{array}{c}\text { Filtering } \\
\text { efficiency } \\
\text { (Percentage } \\
\text { points) }^{3}\end{array}$} \\
\hline & No front & $\begin{array}{l}\text { Unstable } \\
\text { cold front }\end{array}$ & $\begin{array}{l}\text { Part to } \\
\text { whole }^{2}\end{array}$ & No front & $\begin{array}{l}\text { Unstable } \\
\text { cold front }\end{array}$ & $\begin{array}{l}\text { Part to } \\
\text { whole }^{2}\end{array}$ & \\
\hline 2001 & $35.6 \%$ & $23.1 \%$ & $39.35 \%$ & $36.8 \%$ & $42.1 \%$ & $53.36 \%$ & $14.01 \%$ \\
\hline 2002 & $34.1 \%$ & $22.9 \%$ & $40.18 \%$ & $34.6 \%$ & $26.9 \%$ & $43.74 \%$ & $3.56 \%$ \\
\hline 2003 & $51.9 \%$ & $17.7 \%$ & $25.43 \%$ & $30.4 \%$ & $17.4 \%$ & $36.40 \%$ & $10.97 \%$ \\
\hline 2004 & $37.3 \%$ & $22.5 \%$ & $37.63 \%$ & $45.5 \%$ & $27.3 \%$ & $37.50 \%$ & $-0.13 \%$ \\
\hline 2005 & $42.1 \%$ & $21.8 \%$ & $34.12 \%$ & $20.0 \%$ & $24.0 \%$ & $54.55 \%$ & $20.43 \%$ \\
\hline 2006 & $42.0 \%$ & $23.1 \%$ & $35.48 \%$ & $56.3 \%$ & $15.6 \%$ & $21.70 \%$ & $-13.79 \%$ \\
\hline 2007 & $42.3 \%$ & $22.2 \%$ & $34.42 \%$ & $25.0 \%$ & $32.1 \%$ & $56.22 \%$ & $21.80 \%$ \\
\hline 2008 & $43.5 \%$ & $25.5 \%$ & $36.96 \%$ & $33.3 \%$ & $44.4 \%$ & $57.14 \%$ & $20.19 \%$ \\
\hline 2009 & $43.5 \%$ & $20.8 \%$ & $32.35 \%$ & $23.5 \%$ & $41.2 \%$ & & $31.33 \%$ \\
\hline 2010 & $45.4 \%$ & $26.3 \%$ & $36.68 \%$ & $29.7 \%$ & $32.4 \%$ & $52.17 \%$ & $15.49 \%$ \\
\hline
\end{tabular}

The last column in Table 5 shows the efficiency of the filtering for the given year, using percentage points. The mean efficiency of the above described front suggestion algorithm is 12.39 percentage points, which indicates that it is moderately capable of suggesting the presence of unstable cold weather fronts versus the lack of fronts.

By optimizing the parameters of the filtering algorithm, the fluctuation of the filtering efficiency may be minimized. One of the key reasons for the presence of the outliers is the somewhat chaotic nature of transition of weather phenomena.

${ }^{2}$ Part to whole value is calculated using the following formula:

$$
\frac{U C \%}{U C \%+N F \%},
$$

where $U C \%$ is the percentage of days with unstable cold fronts and $N F \%$ is the percentage of days with no fronts - i.e., the values in the previous two columns.

${ }^{3}$ Efficiency is the percentage point increase of part to whole percentage from the unfiltered case to the filtered case. 
Also, when assessing the results shown in the above table, it should be considered, that the input parameters used for the algorithm were chosen heuristically after assessing the input data. In the future, for solving the shortcomings of the front type algorithm, the incorporation of machine learning should be investigated, as a neural network training procedure might result in an algorithm that is capable of producing better results given sufficient training data. Satisfactory training data might be collected using a crowdsourcing-based approach, that is presented in the next section.

\section{Development of a crowdsourcing-based adaptive traffic control system}

Nowadays, via the increasing importance of smart-city platforms, among other reasons, such real-time traffic control systems are becoming more widespread, whose functionality is based on a sufficiently detailed database, which consists of archive as well as constantly updated data. This database could contain - amongst others - information on the given vehicle's or its driver's transport history, meteorological and medical meteorological factors that might influence the driver's alertness.

A crowdsourcing-based approach is introduced for delivering the increased data-need of such a platform. The idea of including a mass of data acquisition sources is based on the model presented in Szántó and Vajta (2017). There, the crowd - i.e., the individual road users - help to gather information about the current state of road surfaces, thus creating an up-to-date database containing information on road surface damages.

For the crowdsourcing-based model to be functioning effectively, large amounts of data are required. The data, as it is established in the previous sections of this paper, might be an archive - e.g., meteorological parameters and measurements from preceding days - or up-to-date information that is acquired continuously by rather heterogeneous data sources - e.g., current road usage statistics and driver vigilance indicators. The former type of data are available via precompiled and - in most cases - publicly available databases, such as those, on which the analysis presented in the previous sections were performed. However, the latter type of data may be collected through many different data acquisition points or sources. These may be smart road infrastructure elements (e.g., lamp posts or in-road sensors), connected (or smart) cars, smartphones, or specific internet of things (IoT) devices.

Such crowdsourcing-based databases that could hold information regarding the above specified road safety conditions, may be used as the foundation for an intelligent traffic control system, that, incorporated with driver-specific driver assistance systems (DAS or ADAS for advanced driver assistance systems) could then adapt their parameters and functionality and ultimately improve traffic safety. 
The research presented in Vécsei and Kovács (2014), and the analysis in the previous sections of this paper indicate that local meteorological conditions, as well as medical meteorological phenomena have a statistically significant connection with road accidents. These results, therefore, justify further research to be carried out in the field of crowdsourcing-based meteorological and traffic data acquisition.

\section{Conclusion and future work}

The purpose of the analysis presented in this article was to assess, at a first reading, whether the endeavor for traffic safety increase based on the detailed investigation of crowdsourced meteorological data is sufficiently founded. The initial inspections presented above were, therefore, carried out using the available databases and utilizing simplified methods. The results introduced above warrant the conduction of further analysis of other traffic safety influencing data, such as:

- accident causes and patterns,

- seasonal and daily variance of accident numbers,

- vehicle type related regulations,

- objective figures for driver vigilance and attention, and

- natural conditions besides weather related data, e.g., pollen concentration.

There are a number of ways that the analysis presented in the previous sections should be improved. Most importantly, the inclusion of the above listed additional data could lead to a more accurate statistical assessment of the relationship between the vehicle driver's objectively perceivable environment and their aptitude for being involved in a traffic accident. Secondly, further investigation of the front type suggestion algorithm may be justified, using monthly or seasonal meteorological parameters rather than yearly data for calculating the temperature variation threshold may lead to higher accuracy. Also, as noted above in Section 2., the utilization of machine learning should be considered for optimizing the parameters of this algorithm. It could also be beneficial for the development of a crowdsourcing-based, real-time traffic control system to develop a probabilistic weather front suggestion system.

Acknowledgements: The authors would like to express their gratitude towards Dr. László Bozó for his valuable input on the mechanics of front type transitions. The authors also owe gratitude to Dr. Kálmán Kovács and the Data Supply Department of the Hungarian Meteorological Service for sharing the extensive local and medical meteorological and accident databases for the purpose of completion of the authors' research. The research reported in this paper was supported by the BME-Artificial Intelligence FIKP grant of EMMI (BME FIKP-MI/SC), and by the EFOP 3.6.1.-16-2016-00014 program of the Ministry of Human Capacities (Disruptive Technologies). 


\section{References}

Brown, I.D., 1994: Driver Fatigue. Human Factors: J Human Fact. Ergonomic. Soc. 36, 298-314. https://doi.org/10.1177/001872089403600210

Bucher, K. and Haase C., 1993: Meteorotropy and medical-meteorological forecasts. Experientia 49, 759-768. https://doi.org/10.1007/BF01923545

Darzi, A., Gaweesh, S.M., Ahmed, M.M., and Novak, D., 2018: Identifying the Causes of Drivers' Hazardous States Using Driver Characteristics, Vehicle Kinematics, and Physiological Measurements. Front. Neurosci 12, 568. https://doi.org/10.3389/fnins.2018.00568

Dúll, A., Fülöp, A., and Mika, J., 2014: A Kérdő-féle frontérzékenységi teszt vizsgálata és kísérlet a továbbfejlesztésére. Légkör 59, 74-77. (In Hungarian)

Everett, J.T., 1879: Studies in relation to the production of pain by weather. Chicago Med. J. Exam $38,253-260$.

Jaroszweski, D. and McNamara, T. 2014: The influence of rainfall on road accidents in urban areas: A weather radar approach. Travel Behav. Soc. 1, 15-21. https://doi.org/10.1016/j.tbs.2013.10.005

Karacasu, M., Er, A., Bilgiç, Ş.,B. Barut, H., 2011: Variations in Traffic Accidents on Seasonal, Monthly, Daily and Hourly Basis: Eskisehir Case. Procedia - Social and Behavioral Sciences. 20, 767-775. https://doi.org/10.1016/j.sbspro.2011.08.085

Ketsketméty, L., Izsó, L., and Könyves T., E., 2011: Bevezetés az IBM SPSS Statistics programrendszerbe. Artéria Stúdió, Budapest. (In Hungarian)

Kovács, Cs., 2013: A lakossági közösségi és egyéni közlekedés jellemzői. Statisztikai tükör, 2013/47, 1-5. (In Hungarian)

KSH, 2019: Közúti gépjármü-állomány, december 31. (2000-),online:

http://www.ksh.hu/docs/hun/xstadat/xstadat_eves/i_ode006b.html (accessed on 05.04.2019.) (In Hungarian)

KSH, 2018: A lakónépesség nem szerint, január 1. (2001-), online: www.ksh.hu/docs/hun/xstadat/xstadat_eves/i_wdsd003a.html (accessed on 05.04.2019.) (In Hungarian)

von Mackensen, S., Hoeppe, P., Maarouf, A., Tourigny, P., Nowak, D., 2005: Prevalence of weather sensitivity in Germany and Canada. Int. J. Biometeorol. 49, 156-166. https://doi.org/10.1007/s00484004-0226-2

Örményi, I., 1975: Érzékenyek vagyunk. Heves Megyei Népújság 26, 9. (In Hungarian)

Sawilowsky, S.S., 2005: Misconceptions leading to choosing the $t$ test over the Wilcoxon Mann-Whitney $\mathrm{U}$ test for shift in location parameter. J. Modern Appl. Stat. Meth. 4, 598-600. https://doi.org/10.22237/jmasm/1130804700

Shahid, S. and, Minhans, A., 2016: Climate change and road safety: A review to assess impacts in Malaysia. Jurnal Teknologi 78(4), 1-8. https://doi.org/10.11113/jt.v78.7991

Szántó, M. and Vajta, L., 2017: Crowdsourcing Techniques for Environmental Information Using Additional Evaluation of Vision Based Driver Assistant Systems. 2017 International Conference on Control, Artificial Intelligence, Robotics \& Optimization (ICCAIRO). Prague, 51-55. https://doi.org/10.1109/ICCAIRO.2017.19

Vécsei, P. and Kovács, K., 2014: Statistical analysis of relationships between road accidents involving personal injury and meteorological variables in Hungary. Időjárás 118, 349-378. 